\title{
Impacts of Pandemics on Economy - Focusing on the Measures and Employee Performance in Banking Industry of Pakistan during COVID-19
}

\author{
Rukhshinda Begum, \\ Lecturer, Department of Commerce \\ University of Karachi, Pakistan \\ Ahsen Mobeen, \\ Chief Manager, Corporate Branch Karachi \\ MCB Bank Limited, Pakistan
}

Doi:10.19044/esj.2020.v16n16p13～URL:http://dx.doi.org/10.19044/esj.2020.v16n16p13

\begin{abstract}
This study deals with the impacts of pandemics on economy with the focus lying on the banking sector of Pakistan. This work centers on the recent pandemic of Corona Virus that instigated in late 2019. COVID-19 is not the single pandemic observed by the nations. However, the span of its outbreak is larger than those occurred earlier. This occurrence has affected the health and life of people. Besides, it is also causing strokes to the economies. Pakistan is one of the developing nations those came across with the hit. Nevertheless, banks are the only business that is operating with almost its full capacity even though many other businesses are either closed or working partially and lockdown is being observed in the country. Responses from 112 bank employees working in Pakistan obtained regarding their stance during COVID-19 and resultant lockdown. The study explores that bank employees in Pakistan are not satisfied with the financial benefits that must have been provided to work in this situation. Moreover, a significant number of employees is also having trouble due to the non-availability of appropriate conveyance facility because public transport is not available under lockdown. This condition, if prevails further, may cause employees' demotivation, reduced productivity and economic slowdown in the long run.
\end{abstract}

Keywords: Economy, Impact, Banking, Pandemic, Coronavirus, Pakistan

\section{Introduction}

Coronavirus pandemic outbreak began in China during December 2019 (McKibbin and Fernando, 2020) and lingers on to the world irrespective of the level at which the economies of these countries are. The earlier 
epidemics of Severe Acute Respiratory Syndromes (SARS) outbreak in 2003 and the outbreak of Influenza in 2013 have been resulted in the massive loss in terms of both health and economy. Hence, Qiu, Chu, Mao and Wu, (2018), uncovered the aspects due to which handling and management of the outcomes of infectious diseases should be considered essential.

Like many other countries, outbreak of novel corona virus termed as COVID-19, emerged in Pakistan during February, 2020 and still continues with no clear timeline for its end. Nevertheless, this outbreak is resulting in huge effects on the health, economy and the society overall. Numerous steps have been taken by the government in order to control the negative effects of COVID-19. However, some areas of the economy are still being neglected. Therefore, this study has made an attempt to address one of such issues.

As a controlling measure, lockdown is being observed in most of the cities of Pakistan. This lockdown has initially covered almost all types of businesses and services except household goods, pharmaceutical and banking. Hence, banking is one of the major sectors of Pakistan's economy that is running with its full service spectrum and staffing requirements in this emergency. Therefore, this paper has revealed some important aspects for keeping the banks opened in this situation of health crisis and their impact on Pakistan's economy.

\section{Research Objective and Scope}

The author has conducted this study with the objective of identifying the weaknesses in decision-making related to the banking business in Pakistan and supporting industry regulators to design useful policies during prevailing crisis.

\section{Research Hypothesis}

H1: Outbreak of a pandemic results in adverse economic impacts due to the inappropriate measures taken for the employees in banking sector of Pakistan during COVID-19

H0: Outbreak of a pandemic do not have any economic impacts due to the inappropriate measures taken for the employees in banking sector of Pakistan during COVID-19

\section{Review of Related Literature}

There are different schools of thoughts to describe pandemic and to differentiate between pandemic and epidemic. However, Morens, Folkers, and Fauci (2009) have studied and discussed about the definition and nature of pandemic in detail. The authors acknowledged that there is not a single accepted definition of a pandemic. However, the understanding may be 
developed through examining the differences and similarities among various diseases discussed as pandemic historically. Pandemic is a disease that; spreads over a large geographic span like plague and cholera, usually moves through person-to-person transmission, has high rates of attack within shorter period and is not necessarily be handled through immunity. It is a disease with some novel modifications. It is infectious, severe and contagious with different transmission mechanisms.

Garrett (2008) studied the economic effects of influenza pandemic during 1918-1919 that caused a high mortality rate in various regions of the United States. 1918 was also the period of First World War. Nevertheless, death rate due to influenza observed higher than that caused by the war. The author welcomes the further analysis on the data presented in this study. This study observed the differences in mortality rate due to influenza pandemic across regions and countries. A large percentage of population suffered from this pandemic comprised the men of ages from 18 to 40 . Thus, the outbreak caused huge economic downturn for the families from whom these persons belonged and consequently for the respective nations. Nonetheless, this pandemic was considered a tragic historical event. It has not been referred to prepare for any such occurrences in future. Influenza was observed greater in heavily populated areas because of its transmission through human contact. Moreover, the death rate in urban areas/cities was higher from that in rural areas based on the author's calculations. Urban/ city areas were densely populated relative to the rural ones that has been the reason of positive correlation between population and influenza death rate. Likewise, non-whites and relatively lower-income persons found to have higher percentage in death rate as majority of non-whites were residing in urban areas with lower income levels. While making an analysis of the income growth in various sectors, it has been evaluated that incomes of the sectors related to healthcare increased whereas it showed a decline in other sectors of economy mainly entertainment and services. Another loss i.e. decrease in human capital due to pandemic had serious economic impacts long after the pandemic. He has opined that potential impacts of any future pandemic are supposed to be much higher and may only be handled to some extent through learnings from past pandemics. Hence, the preparation of governments in order to keep the civilians safe from any future pandemic is of major concern in spite of the advance health care facilities.

Vandegrift, Sokolow, Daszak and Kilpatrick (2010) endorsed the adverse impacts of infectious diseases. The authors are of the view that the transmission of influenza virus in animals and humans is closely connected and increasing thus enhancing the potential for pandemics.

Widespread fatal diseases and resulting deaths have always been a prospective hazard for the nations. Some of the infectious diseases, like 
influenza, are so intensive that outbreak of the same if occurs, affects nations, irrespective the stage of their development and accompany several intensive economic risks. These risks include primarily the costs for the testing and treatment of infected persons, lessen productivity of the ones get infected as well as the ones in family those are responsible to take care of the sick, fear of infection that may result in the closure of businesses and factories in order to maintain social distancing and decline in trade and tourism to avoid spread. Hence, economic influence of such pandemics gets multiplied. Such outbreaks affect various sectors of economy in differing ways. Pharmaceutical and Health Care activities increase and these sectors at one end get benefited. Whereas, the life and health insurance businesses get adversely affected. Other risks, for example; political risks, social risks and economic risks beyond the results of this outbreak are in addition to the outbreak related economic risks. These risks, specifically in developing nations, may only be mitigated if sufficient investments have been made to build and strengthen health care system even with the limited budgets besides accomplishing economic and political tasks. The strategy of quarantine used to be adopted during plague may better work to limit the outbreak of such diseases. Severe acute respiratory syndrome requires immediate research as no vaccine for the same is available. (Bloom, Cadarette and Sevilla, 2018). Juan Yu, Ning Ding and Huan Chen (2020), have highlighted the gaps in controlling COVID-19 spread in China through a case study published after the outbreak in China. However, no apparent measures immediately adopted to restrict its spread in Pakistan. Even though, this study is not catering the complete scope of COVID-19. However, it is important to point out here that several studies related to infectious diseases that caused the loss of human life as well as the economy had been conducted before such huge outbreak in Pakistan.

\section{Research Methodology}

This study analyses the performance of banks during COVID-19. It has made an effort to find whether banking business is being effected during pandemic considering that this is one of the few sectors those are open in the country during outbreak. The author has made a careful study of the earlier works related to pandemics and their outcomes. Besides, the responses from 112 employees working in different banks of Pakistan have also been collected to analyze the hypothesized statements. Responses from the bank employees have been collected through a survey questionnaire that is developed on google doc and the employees' interviews. It has been tried to approach the employees of the banks that are having significant share of transaction volume in the banking sector of Pakistan. 


\section{Results and Discussion}

COVID-19 has been the largely discussed topic since its spread over the world because the same has effected almost every aspect of life worldwide. It somehow verifies the study of Thomas A. Garrett (2008) according to which the preparations deemed to be essential to come across with the effects on pandemic in spite of intensive health care facilities.
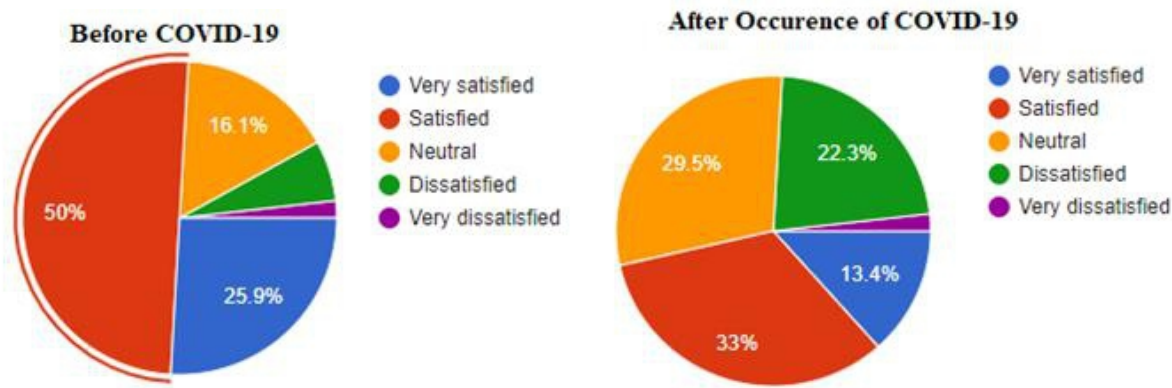

An effort has been made to view its impact on the banking sector and ultimately the economy of Pakistan. 112 responses have been obtained from the employees of SBP member banks in Pakistan. The respondents are comprised of $78 \%$ males and $22 \%$ females, with most of employees under the age bracket of 28-37 years (47\%) followed by the age bracket of 38-47 years (23\%). Most of the employees found to be satisfied with working in banks prior the spread of Corona pandemic. However, level of satisfaction considerably declined after the outbreak.

Mean responses for the volume of transactions in banks after instigation of COVID-19 in Pakistan indicate that there is no significant change in transaction volume. However, the number of injection of new customers declined in banks after the occurrence of COVID-19. Moreover, a significant volume of responses (30\%) reveal that no new customer added after the start of the distress. Besides, the number of walk-in customers also declined.

Appended below is the summary of responses collected with regard to the satisfaction level of bank employees for Safety Measures taken in banks for Employees, Extra Financial Benefit, Conveyance facility to manage during lock down and Work Hours during Pandemic. 


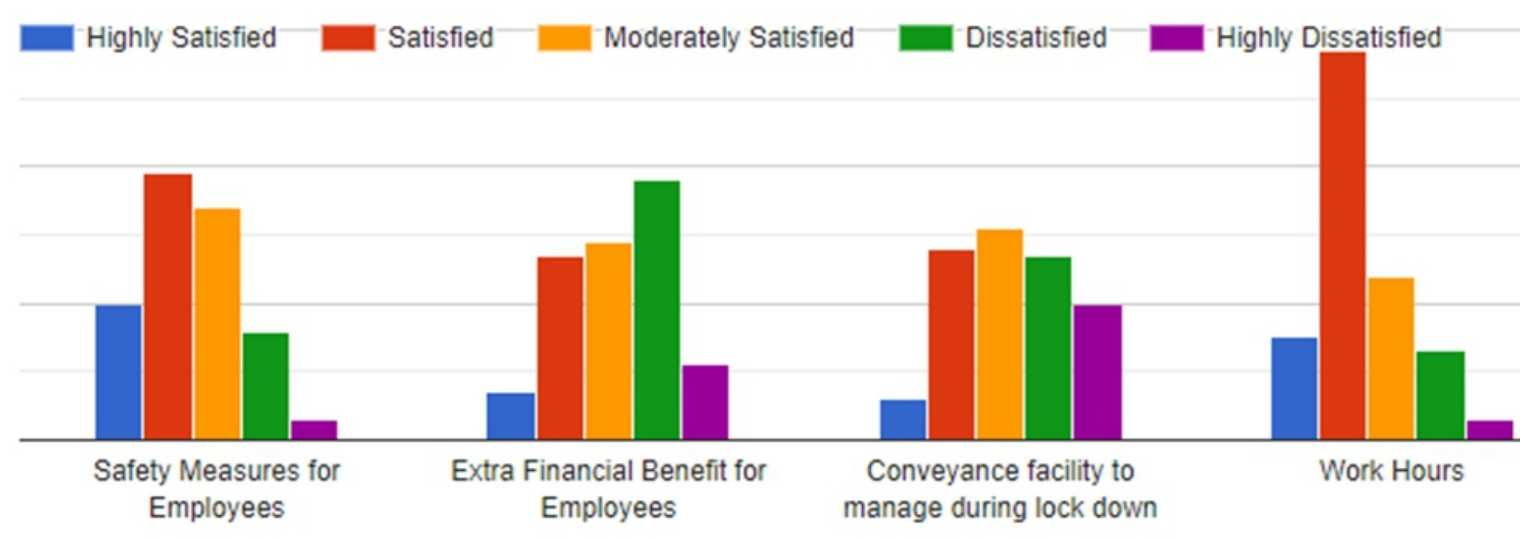

As per the above depiction, most of the employees are satisfied with safety measures and work hours by the banks' management during COVID19. However, most of the employees are not satisfied with the financial benefit, as they are attending the offices and working during such crises. Moreover, the dissatisfaction of a considerable number of employees for the conveyance facility may not be avoided.

The above discussed situation is leading to the probable economic crisis as portrayed in the study of Bloom, Cadarette and Sevilla, 2018. According to this study, the economic effects of pandemic get amplified, mainly due to the increasing costs and declining benefits, under the economic slowdowns. Various other studies have also discussed the adverse impacts of pandemic on health as well as on the economy and society.

\section{Conclusion}

The study under consideration is based on the analysis on reviewed literature as well as the responses collected from bank employees in Pakistan. It may be identified from literature that indication for inappropriate measures, under such a crises, has already been made when SARS occurred. However, no significant steps appeared to be taken by the world economies that caused huge losses when COVID-19 instigated.

While reviewing the responses from bank employees, it has been evaluated that on average the business volume remained the same or declined somewhere. Whereas, the satisfaction level of employees for working in banks after the occurrence of COVID-19, declined. Most of the employees are satisfied with the safety measures and working hours. However, a considerable percentage of employees is having the conveyance problems because the public transport is not available at large due to lockdown. They are also unhappy for not having any extra financial benefits to serve in this situation when everybody wants to be limited to one's home. Furthermore, discussions with some employees, expressed their discomfort with working in such an 
environment, where social distancing is not possible due to a significantly large number of employees working under the limited space in premises.

All the above conclusions lead towards worsening economic condition in the country as a result of Corona pandemic. This is mainly because of lowering transaction volume and declining level of employee satisfaction in banking industry considering that it is the major sector of economy and is the single sector that is operating in Pakistan with its full capacity even in this troublesome situation throughout the world.

\section{Recommendations}

In view of the above discussion and findings, following steps are being suggested to be carried on so as to deal with the recent pandemic and any such occurrence in the future.

- Besides, enhanced safety measures, banks' management should enhance employee motivation in banking sector through some financial benefits, as they are working under the danger.

- Appropriate conveyance facility should be provided to employees to make their attendance to the banks convenient.

- Necessary arrangements should be made at the premises so that all precautionary measures suggested for COVID-19 could be complied for the current situation. Moreover, these arrangements should last onwards to continue operations in any such circumstances in future.

- Notably, learning from the past must be secured, the researches should have been given prime attention by the policy makers in all circumstances and any predictions or recommendations made thereof, must be addressed.

\section{Research Limitations}

This research work is mainly based on the responses from bank employees in Pakistan through questionnaires and interviews. Hence, there may have been the possibility of bias due to the reduced bank timing during lockdown, work pressure, fear of job loss and psychological stress because of COVID-19. Moreover, only telephonic interviews could be conducted because travelling was only allowed for the specific purposes by the government in order to avoid spread of corona virus. Hence, a very limited number of employees could be available for telephonic interviews that might have been produced some particular side of the story.

\section{References:}

1. Bloom , D. E., Cadarette , D., \& Sevilla , J. (2018, June). Epidemics and Economics. Finance \& Developement, pp. 46-49. 
2. Craven, M., Mysore, M., Singhal, S., Smit, S., \& Wilson, M. (2020, March 30). COVID-19: Briefing note. COVID-19: Briefing note.

3. Delivorias , A., \& Scholz, N. (2020, February). Economic impact of epidemics and pandemics. EPRS | European Parliamentary Research Service.

4. Garrett, T. A. (2008, March/April). Pandemic Economics: The 1918 Influenza and Its Modern-Day Implications. Federal Reserve Bank of St. Louis Review, 75-93.

5. McKibbin, W., \& Fernando, R. (2020, March 2). The Global Macroeconomic Impacts of COVID-19: Seven Scenarios. The Global Macroeconomic Impacts of COVID-19: Seven Scenarios.

6. Morens, D. M., Folkers, G. K., \& Fauci , A. S. (2009, October 1). What Is a Pandemic? The Journal of Infectious Diseases, 1018-1021.

7. (2019, January). Outbreak Readiness and Business Impact Protecting Lives and Livelihoods across the Global Economy. World Economic Forum.

8. Qiu,, W., Chu, C., Mao, A., \& Wu, J. (2018). The Impacts on Health, Society, and Economy of SARS and H7N9 Outbreaks in China: A Case Comparison Study. Journal of Environmental and Public Health, 1-7. doi:https://doi.org/10.1155/2018/2710185

9. Vandegrift, K., Sokolow, S., Daszak, P., \& Kilpatrick, A. M. (2010, May). Ecology of avian influenza viruses in a changing world. National Institute of Health.

10. Yu, J., Ding, N., Chen, H., Liu, X.-J., Pu, Z.-H., Xu, H.-J., . . Z Zhang, H.-W. (2020). Loopholes in Current Infection Control and Prevention Practices Against COVID-19 in Radiology Department and Improvement Suggestions. Canadian Association of Radiologists' Journal, 1-7. 